\title{
DECOMPOSIÇÃO IDE NTITÁRIA E INTENSIFICAÇÃo DA EXPERIÊNCIA TURÍSTICA - ENTRE A EMANCIPAÇÃO LOCAL E A INTEGRAÇÃO INTERNACIONAL
}

\author{
António Sérgio Araújo de Almeida
}

\begin{abstract}
Resumo
O protagonismo da experiência na atividade turística mundial reside, em grande parte, no contexto intrapessoal do turista, na organização sistémica do destino turístico e no processo de integração internacional. É intenção do presente trabalho evidenciar oportunidades operacionais, locais e globais que resultam da gestão turística de recursos identitários. Procedeu-se a um cruzamento de resultados obtidos em investigações próprias entre 2010 e 2017 . Conclui-se que dinâmicas comunitárias locais e o processo de intensificação da experiência do turista suscitam a oportunidade de uma decomposição identitária e respetiva estratificação de atributos que se configuram como fatores intensificadores da experiência turística. Deste processo, resultam espaços de convergência de vantagens mútuas, tanto para turistas como para as comunidades locais dos destinos. Globalmente, o turismo, afigura-se como uma ferramenta de conhecimento, integração e consequentemente como veículo promotor da paz.
\end{abstract}

PALAVRAS-CHAVE

Decomposição identitária; emancipação local; experiência turística; integração

\section{BUILDING TOURISM EXPERIENCE THROUGH IDENTITY DECOMPOSITION - BETWEEN LOCAL EMANCIPATION AND INTERNATIONAL INTEGRATION}

\begin{abstract}
The role of experience in world tourism activity resides largely in the context of the tourist, in the systemic organisation of the destination and in the process of international integration. It is intention of this study to highlight local and global operational opportunities, resulting from tourist management of identity resources. This paper is supported by a cross-check of results obtained in our own investigations between 2010 and 2017. It was concluded that local community dynamics and the process of intensification of tourist experience give raise to an opportunity of an identity decomposition and respective stratification of attributes that are configured as intensifying factors of the tourist experience. This process underlines mutual advantages for tourists and local communities and also reveals a tool of knowledge, integration and peace promoting.
\end{abstract}

\section{KEYWORDS}

Identity decomposition; integration; local emancipation; tourism experience 


\section{INTRODUÇÃo}

Em termos internacionais o turismo tem vindo sucessivamente a crescer e a afirmar-se como um fenómeno de dimensão global com impactos culturais, sociais, económicos e ambientais/espaciais/ecológicos. Os impactos mundiais do turismo suscitam a sua compreensão multidisciplinar e interdisciplinar, designadamente no âmbito das áreas de conhecimento que mais têm vindo a determinar a sua evolução.

Nas investigações resgatadas para o presente trabalho constata-se que em turismo e em paralelo com o diagnóstico de recursos deverá haver uma preocupação estratégica de diagnosticar atributos identitários que se consubstanciem em fatores intensificadores da experiência turística.

Assume-se comummente que o turismo vende sonhos que permitam ao indivíduo abandonar as suas tarefas rotineiras, proporcionando-lhe a inserção numa realidade temporária alternativa, sendo o reencontro consigo mesmo, num plano de realização e desenvolvimento pessoal, um dos grandes desafios da atividade turística na atualidade.

A qualidade e intensidade da experiência turística são neste pressuposto um dos grandes desideratos que se coloca ao turismo, enquanto atividade cultural, social e económica. Esta é uma tendência estrutural que diz respeito, em primeira linha, aos turistas mas também aos agentes turísticos, às comunidades locais, aos Estados e à própria sociedade internacional.

No entender de Chang (2018, p. 62)

a atividade turística deve enfatizar e promover a confiabilidade de seus produtos experienciais, particularmente de relaxamento como uma componente experiencial. Além disso, o local de residência é um fator que influencia os valores financeiros percebidos de componentes experienciais uma vez que a residência reflete características e culturas locais.

A própria globalização e os fluxos transnacionais de comunicação e informação elevaram os patamares de exigência em torno da experiência enquanto conceito que permite ao usuário o conhecimento e o desenvolvimento pessoal. Comprar um sonho é algo cada vez mais associado a este setor de atividade económica e a gestão turística enfrenta o desafio óbvio de criação e inovação ao nível das experiências turísticas. A economia da experiência é neste sentido um conceito oportuno que os agentes do setor não podem descurar.

Recorrendo a investigações e publicações próprias, é intenção do presente trabaIho evidenciar as oportunidades que se levantam no âmbito do diagnóstico casuístico de fatores intensificadores da experiência turística assente na decomposição da identidade do destino. A oportunidade e interesse do tema são evidenciados de seguida num enquadramento teórico que alude à oportunidade e interesse do tema, seguido da referência aos procedimentos metodológicos que resultam de trabalhos realizados nos últimos sete anos. O corpo teórico consusbstancia e reforça o cruzamento das referidas investigações desenvolvidas até à atualidade. A complementaridade conceptual de autores e publicações de referência internacional no âmbito da presente área de conhecimento é também um aspeto a referir no âmbito do corpo teórico. 


\section{ENQUADRAMENTO TEÓRICO}

A oportunidade da presente abordagem coloca-se perante as necessidades de turistas, cada vez mais exigentes, a emancipação cultural, social e económica das comunidades locais, bem como perante a afirmação da imagem dos próprios Estados que enfrentam também o desafio de resgatar o turismo enquanto ferramenta de integração.

Fazer turismo implica sair das rotinas do quotidiano. A qualidade e intensidade da experiência turística são o grande fator apelativo dos destinos, assumindo-se a diferenciação do intangível como um fator determinante do marketing turístico. A própria imagem do destino está cada vez mais associada à experiência global desse mesmo destino. Muito para além do descanso, do divertimento e do lazer, o turismo diferencia-se cada vez mais pelo desenvolvimento pessoal que é capaz de proporcionar aos turistas. Os fluxos globais de informação e conhecimento têm vindo a condicionar, também, os níveis de exigência dos turistas e por consequência a massa crítica dos sistemas turísticos:
a escolástica do Turismo assume a intangibilidade como um dos principais fatores que diferencia a oferta turística de outros tipos de produtos (...) sendo a Experiência Turística uma espécie de primado que tem vindo a ser observado como uma prioridade sistêmica com influência na própria ima- gem dos Destinos Turísticos. (Morgado et al., 2016, p. 2)

Um destino turístico terá uma imagem mais consistente na medida em que conseguir implementar uma experiência global devidamente articulada entre os diversos atores locais. Torna-se determinante nesta atitude comunitária um certo sentido corporativo dos agentes locais em prol do imaginário turístico que querem projetar em função da experiência.

Consumos associados às diferenças culturais e sociais e a pretextos para alcançar o desenvolvimento pessoal e a própria emancipação das comunidades locais, são assim uma realidade incontornável, que, não colocando em causa o espaço do turismo de massas, configuram novas visões e estratégias por parte dos destinos. Na perspetiva de Loureiro (2014, p. 7),
podemos afirmar que todo o processo da experiência turística começa com a busca de um destino, e então uma região integrada num contexto de co- municação e marketing que considera não só o alojamento, mas também as características únicas e diferenciadoras da região, pode ser um bónus na criação de uma experiência notável.

A visão da Organização Mundial do Turismo (OMT) para o turismo baseia-se numa análise de contributos da atividade para a construção do bem comum e na criação de plataforma territoriais, culturalmente atrativas e diferenciadas, envolvendo as comunidades autóctones e promovendo a sua emancipação através de uma atividade turística equitativa, responsável e promotora do meio ambiente e cultural. O próprio diagnóstico da identidade material e imaterial dos destinos e envolvimento das comunidades (que 
os promovem enquanto produtos turísticos diferenciados, propiciadores de lucros para si próprias) é um processo que deve ser gerido, observando necessidades locais de educação e formação coletiva, adotando as pedagogias mais eficazes para uma perpetuação de complementaridades. Ou seja, o diagnóstico de recursos identitários, materiais e imateriais, é uma base da definição de produtos turísticos sustentáveis assentes numa visão holística que congrega fatores culturais, sociais, económicos, ambientais e espaciais, tal como preconizado pela Organização Mundial do Turismo e que remonta à própria Declaração de Manila de 1980.

O único, o autêntico na perspetiva objetiva de Wang (1999), o alternativo perante ofertas turísticas massificadas, são assim atributos associados a novos e emergentes produtos turísticos e consequentemente a diversidade territorial e das gentes, remete a identidade para um papel estratégico no âmbito dos sistemas turísticos:

o turismo encara, pois, um paradigma interventivo em termos sociais, não se pautando apenas por conteúdos efêmeros, meramente contemplativos. A assunção identitária das comunidades locais (incorporando a própria oferta turística) e a consequente materialização de seu legado (...) são assumidamente fatores de diferenciação do destino, que suscita envolvimento, conhecimento, formação e inovação. (Almeida \& Pinto, 2017, p. 620)

O exotismo, a interação com outras culturas e a própria transgressão são também conceitos cada vez mais associados ao imaginário turístico e aos novos consumos, refletindo turistas cada vez mais esclarecidos, informados e exigentes. Os cartazes turísticos são infindáveis, materializando justamente uma infinidade de experiências turísticas emergentes, algumas das coisas postas em causa pelo próprio Código Mundial de Ética no Turismo, tais como, Turismo de Vulcões, Enoturismo, Turismo de Aldeia, Ecoturismo, Turismo de Natureza, Turismo Cemiterial, Turismo Negro, Turismo Sexual, Turismo de Favelas, Turismo de Guerra, etc, etc.

De acordo com a obra de Amirou (2007), para além de uma simples transação comercial, o turismo apresenta-se claramente como uma troca simbólica. Sustenta o autor que como contrapartida pelo dinheiro gasto, o cliente espera mais do que prestações hoteleiras, ele quer um espaço de jogo e de liberdade, um ar de "irresponsabilidade" limitada em que possa jogar sob o olhar benevolente e compreensivo da instituição turística.

\section{Procedimentos metodológicos}

O presente trabalho enquadra o turismo como atividade global que proporciona o conhecimento mútuo dos povos, assumindo a experiência como ferramenta que no terreno proporciona este desiderato. $\mathrm{O}$ artigo alude ao turismo enquanto atividade local e global de integração, resgatando a decomposição identitária e a consequente estratificação de fatores intensificadores da experiência como elementos emancipadores, tanto na perspetiva do turista como no contexto das comunidades locais e dos próprios 
Estados. Recorrendo a contributos das Relações Internacionais e das Ciências do Turismo, é intenção do artigo sublinhar as complementaridades naturais e informais entre as dinâmicas do sistema internacional e a atividade turística mundial, o que nem sempre é evidenciado na bibliografia e nos trabalhos académicos realizados.

O processo de intensificação da experiência turística é uma das linhas de investigação do autor que proporcionou o cruzamento de resultados no âmbito de diversas investigações próprias realizadas sobre a temática. Turistas, comunidades locais e respetivos representantes, agentes turísticos e demais forças vivas, autarcas e responsáveis institucionais e políticos, integram o rol de entrevistas realizadas no âmbito dos trabalhos publicados que serviram de suporte ao presente artigo.

Foi intenção do presente trabalho apresentar um enquadramento original assente nos padrões espaciais e experienciais entretanto investigados. A preocupação essencial incidiu no diagnóstico de coerências experienciais nas referidas investigações que ilustrassem nexos de causalidade entre a intensificação da experiência turística e um protagonismo de contributos identitários para a sustentabilidade dos territórios e para a emancipação cultural, social, económica e espacial das respetivas comunidades locais. $O$ turismo é uma realidade das relações internacionais, pelo que, é fundamental a sua compreensão enquanto ferramenta de integração internacional. O seu estatuto de "Indústria da Paz", tal como preconizado pela Organização Mundial de Turismo (OMT) e pela própria Organização das Nações Unidas (ONU) atesta afinal esta importância global.

\section{O SENTIDO ESTRATÉGICO DA IDENTIDADE}

Enquanto que no Poder da identidade Castells (1999) sublinha a identidade como uma espécie de fonte de significado e experiência de um povo, Bauman, na sua obra (2005) assinala a identidade como um processo contínuo de construção, ficando sempre incompleta e ajustando-se à mecânica de uma modernidade líquida. Nesta última perspetiva, o turismo, mercê da sua dimensão e impactos globais, será um dos fenómenos que mais contribui para este processo de liquidificação local, nacional e internacional.

O cruzamento das obras destes dois autores é fundamental para invocar o status quo da atividade turística mundial, nomeadamente no que concerne ao poder dos ícones para a afirmação e diferenciação dos territórios e pela facilidade de comunicação, aprendizagem e integração perante novas ideias e valores. Se por um lado, há uma crescente apropriação simbólica da realidade por parte dos povos, por outro há também uma propensão para a aprendizagem e integração de novos símbolos, o que é consubstanciado, designadamente, no aumento progressivo dos fluxos do transnacionalismo:

apesar das características ambientais, culturais e sociais serem elementos constitutivos e diferenciadores dos lugares, é precisamente a sua identidade que confere originalidade e singularidade aos lugares e os distingue de outros. É neste contexto que surgem outros conceitos fundamental para esta temática: a autenticidade e assunção identitária. (Malheiros, Lourenço \& Almeida, 2016, p. 72) 
A identidade enfrenta uma realidade ambivalente no âmbito do sistema internacional, porquanto é pretexto de partilha de conhecimento, aprendizagem e consequentemente constitui um fator de respeito mútuo, mas, por outro lado, é motivo de competição, regionalismos e conflitos étnicos. Ou seja, os valores identitários são simultaneamente pretexto de cooperação e de conflito. Consciente desta problemática, a Organização das Nações Unidas e sobretudo a Organização Mundial de Turismo têm vindo a promover a identidade enquanto conceito agregador de culturas diferentes, sendo o turismo uma ferramenta global passível de alcançar este desiderato.

Segundo Wang \& Chen (2015, p. 26)

o impacto do sentido de residência na identidade local e o seu efeito moderador sobre residentes e atitudes em relação ao turismo indicam que em turismo urbano os gestores, devem estar cientes das discrepâncias possíveis, perceptuais, que podem transparecer entre moradores de tipologia diferente. Com uma melhor compreensão de tais impactos, os gestores podem simplificar as suas estratégias de marketing internas, utilizando o comprimento-de-residência como uma base para otimizar seus esforços de marketing e resultados.

Havendo uma tendência para valorização local dos ícones e dos sistemas de valores, importará promover o envolvimento das comunidades, fomentando a apropriação dos seus símbolos e afirmando-os como produtos sustentáveis que contribuam para o seu desenvolvimento e emancipação. Para além do diagnóstico local de recursos, torna-se assim fundamental o diagnóstico de mecanismos sociais que proporcionem uma apropriação simbólica da realidade por parte das comunidades locais.

O turismo, enquanto fenómeno cultural, social e económico, depende em grande medida dos processos de integração entre turistas e comunidades locais, sendo a interação um pressuposto incontornável para proporcionar um ambiente de partilha convergente em torno das mais-valias turísticas locais (Salvador, Boavida \& Almeida, 2016, p. 36). Em turismo torna-se essencial a perceção de atributos identitários passíveis de usufruto experiencial. Este será afinal um fator fundamental no âmbito da exportação de valores e património imaterial, tendo como suporte precisamente o turismo enquanto atividade que privilegia a exportação. Ou seja, para além de exportar serviços, o turismo enfrenta também o desafio de exportar ideias e valores, promovendo assim as culturas locais.

De acordo com Thurnell-Read (2017, p. 59) é “importante que esta relação entre o turismo e identidade seja narrada e executada". O diagnóstico de atributos identitários passíveis de gestão da experiência turística, acaba por consubstanciar-se numa espécie de decomposição identitária, proporcionando assim um cariz operacional ao conceito identidade, assumidamente encarado como algo abstrato, subjetivo e complexo. Agregando o património, a cultura (material e imaterial) e um envolvimento comunitário com a transmissão desta alma coletiva que reflete o pulsar histórico e o momento presente, estão reunidas condições para corresponder ao primado da atividade turística atual assente na valorização da autenticidade nos pressupostos já assumidos anteriormente: 
reside aqui em grande medida "O Poder da Identidade" e a "Assunção Identitária" das comunidades locais que enfrentam um desafio crucial: assumir nas suas mãos os seus próprios destinos. Coloca-se desta forma a questão de quem deve assumir a identidade e a resposta mais pragmática, parece ser aquela que aponta para as próprias comunidades locais, dado que, são elas em primeira instância que estão em condições de apresentar um conceito essencial à atratividade do destino turístico: a autenticidade.

(Malheiros, Lourenço \& Almeida, 2016, pp. 72-73)

Se por um lado, é inegável um imaginário turístico coletivo que alude à autenticidade como uma espécie de primado que é confirmado, ou não, pela forma subjetiva como os turistas viveram determinado destino ou experiência, também não deixa de ser verdade que há ferramentas capazes de conferir objetiva e cientificamente a autenticidade de uma prática ou de um objeto, como por exemplo, o carbono 14. Enfatizando a perspetiva de Wang (1999), segundo a qual há uma valorização turística das práticas e dos objetos originais, importará assim continuar a investigar atributos identitários que são resgatados pelo turista em contextos de experiência global do destino.

Os próprios pressupostos de sutentabilidade turística presumem esta assunção de responsabilidades comunitárias em torno dos seus recursos culturais, sejam materiais ou imateriais, sendo neste contexto o legado cultural uma base de sustentação da atividade turística:

para além de uma lógica associada à massificação, ou, por outro lado, a uma tentativa de afirmação das identidades, os processos inerentes à globalização geram impactos significativos em várias atividades políticas, económicas, sociais e culturais. A globalização massifica, mas também promove identidades. (Almeida, 2010, p. 40)

A identidade é um conceito aberto, transversal, compósito, dinâmico e subjetivo. A sua complexidade será atenuada numa perspetiva de análise das motivações turísticas, sobretudo, no âmbito do conceito central "autenticidade".

\section{A IDENTIDADE COMO PRETEXTO TURÍSTICO DE CONVERGÊNCIA DE VANTAGENS MÚTUAS}

O conhecimento e um desejado desenvolvimento pessoal e coletivo são aspetos fulcrais nos sistemas turísticos atuais, cujos espaços de intervenção social exorbitam a própria realidade turística:

o diagnóstico da matriz identitária e o desenvolvimento integrado da oferta turística possibilitam uma experiência partilhada, global e determinante que permite criar um produto atrativo e afirmar e diferenciar a própria imagem do destino, incrementando a sua capacidade de retenção. (Salvador, Boavida \& Almeida, 2016, p. 45) 
O consumo turístico de atributos identitários é assinalado por uma certa lentidão suscitada por uma necessidade intrínseca do turista de se "entranhar" no conhecimento, facto essencial para a promoção da capacidade de retenção turística do destino. Por outro lado, é vulgarmente aceite que o conhecimento é um fator essencial de integração o que configura novos desafios e responsabilidade para os sistemas turísticos.

Segundo Besculides, Lee e McCormick (2002, p. 306)

as comunidades locais podem realizar benefícios culturais do turismo de duas formas. Primeiro, o turismo expõe o visitante para outras culturas e pode resultar em benefícios, tais como a tolerância e a compreensão. Em segundo lugar, o ato de apresentar a cultura aos forasteiros reforça a ideia do que significa viver em comunidade, reforçando assim o sentido de identidade, orgulho, coesão e apoio.

O turismo tem vindo a assumir protagonismo pedagógico e emancipador em contextos comunitários associados a lógicas de educação não formal e informal. Inúmeros exemplos ilustram práticas locais, que, para além de proporcionarem rendimento próprio, implementam, por esta via, ciclos viciosos de apropriação simbólica da realidade e, por consequência, promove-se a auto-estima coletiva dessas mesmas comunidades:

aspira-se assim a uma lógica estratégica de convergência de vantagens mútuas, aproximando autóctones e turistas, proporcionando benefícios econômicos e sociais aos primeiros e experiências únicas aos segundos. Os agentes turísticos enfrentam (...) o duplo desafio, que consiste, por um lado, no diagnóstico de mecanismos comunitários de envolvimento (...) por outro lado, no diagnóstico de fatores intensificadores da experiência, fazendo jus ao primado da experiência turística. (Almeida \& Pinto, 2017, p. 617)

Este é um processo que se encontra em aberto e acaba por ser também um desafio complexo na medida em que existem inúmeras barreiras, de variada índole, no âmbito daquele que é um grande desafio da atividade turística mundial: a diferenciação do intangível. A matéria tem vindo a evidenciar complexidades ao longo dos últimos anos e a reequacionar as políticas e estratégias nos destinos.

$\mathrm{Na}$ definição de produtos turísticos, as especificidades comunitárias, incluindo as suas mentalidades, acabam por ser encaradas no mesmo patamar que os recursos, dado que esse conhecimento prévio é determinante para aferir mecanismos de envolvimento local e de apropriação simbólica da realidade:

a própria hospitalidade é cada vez mais encarada de forma transversal e compósita, incorporando um somatório de experiências, seja no domínio da gastronomia, no âmbito da animação turística ou da própria interação com a comunidade local. Esta questão influencia incontornavelmente a capacidade de retenção turística e a própria Imagem do destino. (Xavier \& Almeida, 2017, p. 328) 
A coesão sistémica dos destinos remete-nos para questões estruturais e complexas tais como as mentalidades e a propensão para uma desejável união e articulação de esforços no desenvolvimento de produtos turísticos:

é, portanto, importante equacionar mecanismos sociais que podem ser desencadeados nos sistemas turísticos, proporcionando novas atitudes coletivas tendo em vista uma Assunção Identitária, que, sob determinadas condições pode resultar em turismo sustentável e ofertas diferenciadas, reflectindo assim a diversidade concentrada do território português. A globalização é em grande parte alimentada pelas diferenças e especificidades dos ícones. (Almeida, 2010, p. 40)

Não pode, contudo, escamotear-se a ocorrência de "encenações" para turista usufruir. A "turistificação" é uma realidade incontornável e que evidencia uma outra faceta associada à instrumentalização mercantil de atributos desvirtuadamente associados às identidades locais.

O turismo de pequena dimensão valoriza e promove as identidades, as diferenças, desejavelmente em contextos culturais, sociais e económicos de integração. O respeito pelas diferenças e a valorização das especificidades culturais e ambientais será afinal de contas um dos grandes requisitos para sustentar o turismo enquanto indústria que fomenta a aproximação dos povos. Esta realidade global do turismo em torno da busca do conhecimento e respeito pela diferença acaba por assumir um potencial de integração incontornável, passo essencial para a promoção da paz à escala internacional.

No entendimento de Benur e Bramwell, (2015, p. 221) "esta diversificação dos produtos num destino baseia-se, em grande parte, num número de nichos de mercado, produtos em pequena escala". Como alternativa, produtos de nicho do destino podem ser utilizados em processos integrativos, com turistas interessados em diversos produtos de nicho e com os produtores destes produtos potencialmente com êxito, a cooperar juntos.

Esta visão partilhada pela OMT acaba por ser fundamental no âmbito da estrutura internacional em que se insere na convicção de que a própria globalização deverá ser encarada como um processo passível de valorizar as especificidades culturais, sociais e ambientais. Fenómeno estrutural e profundamente marcado pela massificação, a globalização deverá também ser encarada e resgatada nos pressupostos em que promove e facilita os processos de comunicação e a valorização das identidades à escala mundial. Nunca as identidades tiveram tantas oportunidades de "exportação" mercê das condições inerentes à globalização.

\section{A EXPERIÊNCIA TURÍSTICA ENQUANTO MATERIALIZAÇÃo DA IDENTIDADE}

Globalmente, o turismo tem vindo a valorizar as atividades que privilegiam a aquisição de conhecimento, tanto da parte dos turistas como das comunidades locais. Este pressuposto acaba por ser fundamental na valorização da experiência enquanto 
ferramenta de desenvolvimento pessoal dos turistas e na apropriação dos recursos locais como base de desenvolvimento comunitário.

A Escola Finlandesa (LEO, 2009) ao conceber a pirâmide da experiência turística especifica seis fatores essenciais no âmbito do processo de intensificação da experiência turística. A História, a Perceção Multisensorial, a Individualidade, a Interação, o Contraste e a Autenticidade, são a base da Pirâmide e acabam por reforçar a importância de alguns atributos identitários enquanto fatores promotores da experiência. É um processo de estratificação aberto, sendo que a gestão da experiência turística deverá observar a oportunidade dos atributos selecionados no âmbito de cada destino em concreto.

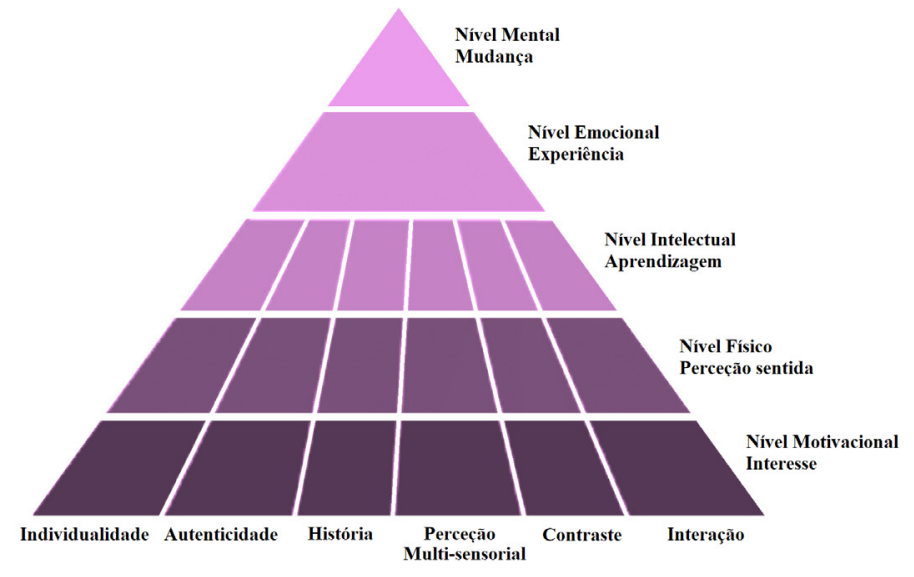

Figura 1: Pirâmide da experiência turística

Fonte: adaptado de Tarssanen e Kylänen, 2005

O presente modelo sustenta um processo de intensificação da experiência turística que culmina com a mudança mental do turista. A experiência transforma o turista e essa transformação é tanto maior, quantos mais atributos e quanto mais intensa for a experiência. Ganha assim oportunidade o conceito gestão da experiência turística no âmbito das especificidades do destino.

Investigações realizadas no âmbito da Feira do Fumeiro de Montalegre, da Feira do Cavalo da Golegã, do comboio histórico a vapor no Alto Douro Vinhateiro, do património judaico em Belmonte, de bairros típicos de Lisboa, do Palácio Nacional de Mafra e das Solenidades da Semana Santa de Braga, evidenciam a arte, a história e as estórias, as tradições e os saberes populares, as lendas e as superstições, as dinâmicas comunitárias e as suas apetências para o envolvimento, a interação, a partilha e a integração como fatores intensificadores da experiência turística.

Em causa estão fatores que, devidamente integrados nos processos de desenvolvimento turístico e devidamente promovidos, condicionam o próprio imaginário e poderão proporcionar o desejado contraste, típico de quem abandonou relações sociais frias e impessoais. A própria correspondência da experiência perante as expectativas criadas e o balanço final da experiência, poderão também assumir-se como fatores intensificadores da experiência: 
a decomposição da Identidade local e a sua materialização enquanto Experiência Turística, presume o evidenciar de valores diversos, tais como a História e Estórias, o Património Material e Imaterial, as Tradições e Saberes Populares. A interação e a integração, assentes em regimes de reciprocidade entre Turistas e Comunidades Locais, são essenciais para alcançar um propósito emancipador da Oferta Turística. (Almeida, 2016, p. 281)

O destino turístico enfrenta este desafio que consiste no seu posicionamento local e internacional em função dos impactos emocionais que pretende assumir tendo em vista o sentimento turístico despertado, a integração numa determinada aprendizagem e a imagem que pretende promover. Também da conjugação devidamente articulada de todos estes processos resulta a experiência turística, encarada cada vez mais numa perspetiva complexa, agregadora e estratégica.

O conceito de sustentabilidade do destino turístico, observando as realidades culturais, sociais, económicas e ecológicas, implica desejavelmente uma espécie de ciclo vicioso que suscita uma apropriação de práticas sustentáveis por parte das comunidades que, tendencialmente, as perpetuam em função dos resultados vantajosos obtidos. Neste sentido, será adequado abordar o conceito de comunidades turísticas que se organizam devidamente para a sua diferenciação e sustentabilidade, designadamente através de uma atitude comunitária proativamente corporativa, consciente dos caminhos a percorrer, investindo, por exemplo, na formação dos mais jovens. Por outro lado, e no entendimento de Nunkoo e Gursoy, (2012, p. 264) os

pesquisadores também devem entender que o apoio à atividade turística não reside apenas nas atitudes dos residentes perante os impactos do turismo, mas também em fatores mais complexos tais como as suas identidades que se assumem de acordo com investigações como um guia para os comportamentos que servem afinal para verificar e manter os autosignificados associados a uma identidade.

\section{EXPERIÊNCIA TURÍSTICA COMO FERRAMENTA DE INTERAÇÃO E INTEGRAÇÃo}

O turismo é uma das mais significativas atividades económicas. Assume um protagonismo global. Esta importância não tem sido acompanhada pelos decisores políticos, sendo que está em causa uma atividade com potencial de intervenção social à escala planetária. Na perspetiva de Farmaki (2017, p. 537) "enquanto a ciência política proporciona teorias, métodos e abordagens perspicazes em estudos de turismo, o turismo, em si, tem sido largamente ignorado pelos cientistas políticos, apesar de sua proeminência como um fenómeno político". Este paradoxo tem inibido este papel interventivo do turismo, nomeadamente naquilo que a atividade potencialmente representa enquanto ferramenta de integração por via do conhecimento e respeito mútuo dos povos: 
as identidades, os símbolos, os ícones, ao invés de pretextos para competir e até para motivar conflitos, são (também) espaços de oportunidade para a partilha, para o conhecimento mútuo e para a valorização e aproximação de culturas. A apropriação simbólica da realidade vai para além da competição e assume pretextos de partilha e de convergência de vantagens mútuas entre Turistas e comunidades locais visitadas. (Almeida, 2016, p. 280)

A dimensão internacional do turismo, enquanto fenómeno cultural, social e económico, confere-lhe um estatuto de construtor global de experiências promotoras do conhecimento mútuo dos povos, o que proporciona interações diversas e generalizadas, aprendizagens, emancipação, conhecimento e consequentemente, integração:

consequentemente, refere-se às respostas que sugerissem algum tipo de importância pessoal percebida do resultado da viagem. Esta dimensão inclui quatro subdimensões principais - reforçando as relações sociais, o desenvolvimento intelectual, auto-descoberta e superando desafios físicos. Na primeira subdimensão, desenvolvimento social, os entrevistados observaram que foi o resultado da interação com os outros durante a viagem que foi um fator significativo na sua experiência memorável (Tung \& Ritchie, 2011, p. 1379)

A visão da Organização Mundial do Turismo tem como fulcro a construção do bem comum e a criação de plataformas territoriais, culturalmente atrativas e diferenciadas. Na linha da Declaração de Manila de 1980, o objetivo consiste em envolver as comunidades autóctones, promovendo a sua autoestima através de uma atividade turística responsável e promotora dos seus recursos com base numa gestão participativa.

De acordo com Chen e Rahman (2017, p. 8),

quando um turista procura uma experiência profunda em relação a uma nova cultura, o turista estará mais aberto para interagir com a a referida cultura, e no processo estará mais propenso ao seu usufruto. Além disso, não há nenhuma dúvida de que o maior nível de contacto cultural é associado a um maior conhecimento adquirido, que é outra dimensão das experiências memoráveis. Uma melhor compreensão da nova cultura, propicia uma maior exploração e consequentemente, adquirir novos conhecimentos sobre a cultura.

De resto, numa visão moderna e sem qualquer menosprezo pela oferta Sol e Mar, soluções opostas às enunciadas corresponderiam a um paradoxo turístico, pondo em causa o património que é, em primeira linha, a sua própria razão de ser. O turismo é progressivamente encarado como uma atividade social que, sob determinadas circunstâncias, pode contribuir para enriquecer a sociedade do conhecimento:

a assunção desta política no turismo, perpassando esferas de atuação de todo o sistema turístico, desde comunidades locais e respetivos agentes, Estados e Organizações Internacionais, contribuirão para resgatar o melhor 
que o Turismo pode dar enquanto ator internacional que contribui para a integração dos povos e consequentemente para uma ordem internacional que favorece progressivamente a Paz. (Almeida, 2016, p. 283)

Esta convicção é tanto mais importante quando é a própria Organização Mundial do Turismo a enaltecer, no seu discurso institucional, os virtuosismos do turismo enquanto "Indústria da Paz", apesar de, em termos técnicos, não estarmos em rigor perante uma atividade industrial mas antes no âmbito de uma espécie de constelação de serviços:

esta necessidade crescente instala-se progressivamente na própria psicologia das organizações e nos próprios atores do Sistema Internacional, e vai afirmando novas formas de planejamento e de conceitualização de produtos, que permitam a emersão de um lado da nossa humanidade, o qual, não pode correr o risco de ser suprimido. Portanto, cada vez mais a oferta turística é encarada sob uma perspetiva de espaço de vivência que proporciona o emergir de um estado de consciência elevado ao respectivo usuário. (Almeida \& Pinto, 2017, p. 616)

A especificidade do intangível associada à imprevisibilidade da realização mais íntima do sujeito levantam discussões éticas. Ofertas associadas ao turismo sexual, ou ao turismo no âmbito do consumo de drogas, não podem ser escamoteadas. O facto de observarmos determinadas condutas deontológicas e éticas, consagradas nomeadamente no Código Mundial de Ética no Turismo, não nos deve inibir de estudar realidades que inequivocamente integram a própria natureza humana, tanto no plano individual como no contexto das organizações sociais, mesmo assumindo a consciência plena da necessidade da sua eventual condenação, ética, moral e social. O fascínio do turismo em ambientes alternativos reside também na compreensão destes fenómenos, na medida em que proporcionam uma outra visão, uma melhor compreensão do ser humano.

De acordo com Tung e Ritchie (2011, p. 1369)

devido à natureza altamente subjetiva da experiência turística, os gestores do destino devem ter em conta que as experiências memoráveis para turistas são uma matéria, também, da sua responsabilidade, tanto que, podem definir serviços, eventos e atividades, objetivamente definidos no âmbito da proposta experiencial. Assim, importa compreender a essência subjacente das experiências memoráveis para que os gestores do turismo possam aumentar a probabilidade de fornecer aos turistas aquelas experiências que são especiais, queridas e verdadeiramente memoráveis.

\section{CONSIDERAÇÕES FINAIS}

A identidade enquanto conceito passível de afetar proactiva e estrategicamente a vida das comunidades, enfrenta uma realidade ambivalente no âmbito do sistema internacional. É a própria Organização das Nações Unidas que através da Organização 
Mundial de Turismo tem feito um esforço para enfatizar a vocação estratégica da identidade enquanto ferramenta agregadora de culturas e promotora da paz.

O turismo, enquanto atividade liberal, económica e marcadamente exportadora, mercê do seu cariz compósito e socialmente transversal, surge nas relações internacionais com uma espécie de ator informal que vai alcançando este desiderato. A identidade enquanto ferramenta de integração acaba por dar uma resposta pedagógica e emancipadora ao cariz conflituoso e desagregador que a mesma identidade encerra. Os regionalismos exacerbados acabam por ilustrar este cariz de conflitualidade identitária e por chamar à colação o próprio conceito de Estado-nação, tal como visto recentemente na Catalunha. Ou seja, se por um lado, a afirmação identitária é motivo de conflitos territoriais e lutas de soberania e autodeterminação, na atividade turística mundial a identidade surge como pretexto de conhecimento, valorização e respeito mútuo entre povos e sistemas de valores e consequentemente integração.

De acordo com Farmaki (2017, p. 532),

com base na premissa de que a atividade turística é um fenómeno social, defensores da hipótese afirmam que o contacto proporcionado pela atividade pode aumentar a compreensão entre as pessoas de raças, origens, culturas e nacionalidades diferentes. A ideia que o contacto com visitantes esbate estereótipos negativos reforça a visão da literatura e que tem vindo a reforçar o turismo como um contributo assumido para a paz mundial.

O poder global do turismo tem vindo de facto a resgatar a identidade como pretexto de conhecimento mútuo dos povos. Esta resposta de integração poderá continuar a ser reforçada e estrategicamente implementada, na medida em que os destinos forem capazes de compreender e assumir nas próprias mãos as suas identidades, decompondo-as através da definição de atributos que se afirmem como fatores intensificadores da experiência turística. Reside também neste pressuposto um aproveitamento do potencial integrador das identidades. Para além da assumida importância do diagnóstico de recursos como passo fulcral na definição de produtos turísticos, importa perspetivar este procedimento de uma forma mais ampla enquanto diagnóstico de recursos identitários, porquanto nesta última perspetiva assumem-se nas práticas de gestão as dinâmicas e o envolvimento comunitários no processo.

Turistas e comunidades locais são emancipados mútua e diariamente. Os primeiros, através da realização intrapessoal resultante da definição e intensificação da experiência turística. Os segundos, através dos dividendos culturais, sociais e económicos que resultam os fluxos turísticos. Diagnosticar e definir atributos identitários que se consubstanciam em fatores intensificadores da experiência turística é um dos grandes desafios que se colocam aos destinos. Esta questão suscita uma visão estratégica local e uma assunção de responsabilidades a nível internacional, sob pena de desperdício de um grande fator de integração à escala global.

Os fatores intensificadores da experiência turística são desejavelmente observados pelo gestor que procura proporcionar vivências alternativas, passíveis de resgate pessoal para o desenvolvimento, e, simultaneamente, potenciadores da emancipação coletiva e 
da integração. Assim, a arte, a história e as estórias, as tradições e os saberes populares, as lendas e as superstições, as dinâmicas comunitárias e as suas apetências para o envolvimento, a interação, a partilha e a integração surgem como fatores intensificadores da experiência turística que estão direta ou indiretamente conotados com os valores identitários, seja numa perspetiva Anthropos, num contexto Oikos, numa análise Chronos ou numa visão Ethos.

A integração destes fatores nos processos de desenvolvimento turístico condiciona o próprio imaginário e poderá proporcionar um contraste de vivências, característico de quem resgata a atividade turística para abandonar temporariamente o quotidiano social em prol de vivências comunitárias. Desta forma, a própria correspondência da experiência perante as expectativas criadas e o balanço final da experiência, poderão também assumir-se como fatores intensificadores da experiência: "o cunho (...) a predisposição comunitária local e a organização (...) impõem um ritmo e uma agenda formais, materializados, em grande parte, em um programa (...) que acaba também por condicionar a experiência global" (Almeida \& Pinto, 2017, p. 622).

Estamos, contudo, perante um processo complexo e sensível, tanto mais que a radicalização psicográfica, ou seja, a aventura, o perigo e a própria transgressão, acabam por ser, em determinados contextos, fatores que intensificam a experiência mas simultaneamente deverão ser alvo de cuidados acrescidos por parte dos gestores turísticos, incluindo a aplicação de legislação e a salvaguarda de valores morais e éticos. A diferenciação do intangível em turismo e os seus contributos para uma sociedade global mais solidária é assumidamente uma área de conhecimento emergente e um dos grandes desafios da atividade turística mundial.

\section{REFERÊNCIAS}

Almeida, A. S. A. (2010). The inter-community competition as a factor for sustainability and differentiation of tourism product - the case of National Park of Peneda Gerês. European Journal of Tourism, Hospitality and Recreation, I(1), 39-50.

Almeida, A.S. A. (2016). O turismo como ator nos processos de integração do sistema internacional - a conceção da oferta turística como ferramenta de interação cultural. In José Dantas P. et al., Animação sociocultural, globalização, multiculturalidade, educação intercultural e intervenção (pp. 277-284). Chaves: Intervenção.

Almeida, A. S. A. \& Pinto, R. (2017). Religiosity and tourism: the primacy of experience. Bol. Mus. Para. Emílio Goeldi. Cienc. Hum.,12(2), 615-627.

Amirou, R. (2007). Imaginário turístico e sociabilidades de viagem. Porto: APTUR - Estratégias Criativas.

Bauman, Z. (2005). Identidade. Rio de Janeiro: Jorge Zahaer.

Benur, A. \& Bramwell, B. (2015). Tourism product development and product diversification in destinations. Tourism Management, 50, 213-224.

Besculides, A., Lee, M. \& McCormick (2002). Residents' perceptions of the cultural benefits of tourism. Annals of Tourism Research, 29(2), 303-319.

Castells, M. (1999). O poder da identidade. São Paulo: Paz e Terra. 
Chang, S., (2018). Experience economy in hospitality and tourism: gain and loss values for service and experience. Tourism Management, 64, 55-63.

Chen, H. \& Rahman I (2018). Cultural tourism: an analysis of engagement, cultural contact, memorable tourism experience and destination loyalty. Tourism Management Perspectives, 26, 153-163.

Farmaki, A. (2017). The tourism and peace nexus. Tourism Management, 59, 528-540.

Loureiro, S. (2014). The role of the rural tourism experience economy in place attachment and behavioral intentions. International Journal of Hospitality Management, 40, 1-9.

Malheiros, A. P., Lourenço P. C. \& Almeida, ASA (2016). Some contributions to the assumptive identity of Portugal's jewish heritage - the case of Belmonte. Revista Portuguesa de Estudos Regionais, 43, 69-88.

Morgado, A., Pires S., Rodrigues, M., Simões, T. \& Almeida, ASA (2016). Mitos e lendas como contributo para a diferenciação da experiência turística - o caso dos túneis do Palácio Nacional de Mafra, Portugal. Marketing Q Tourism Review, 1(1), 1-21.

Nunkoo, R. \& Gursoy, D. (2012). Resident's support for tourism - an identity perspective. Annals of Tourism Research, 39(1), 243-268.

Salvador, V. M. M., Boavida, A. T. F. V. \& Almeida, ASA (2016). Contributos para a compreensão da integração turística no âmbito da interação cultural - os casos da feira do cavalo da Golegã e do comboio histórico a vapor no Alto Douro Vinhateiro. Tourism and Hospitality International Journal, 6(1), 35-54.

Tarssanen, S. \& Kylänen M. (2005). A theoretical model for producing experiences - a touristic perspective. In M. Kylänen (Ed.), Articles on Experiences 2 (pp. 132-151). Rovaniemi: Lapland Centre of Expertise for the Experience Industry.

Thurnell-Read, T. (2017). What's on your bucket list?: tourism, identity and imperative experiential discourse. Annals of Tourism Research, 67, 58-66.

Tung, V. \& Ritchie, J. R. (2011). Exploring the essence of memorable tourism experiences. Annals of Tourism Research, 38(4), 1367-1386.

Wang, N. (1999). Rethinking authenticity in tourism experience. Annals of Tourism Research, 26(2), 349-370.

Wang, S. \& Chen, J. (2015). The influence of place identity on perceived tourism impacts. Annals of Tourism Research, 52, 16-28.

Xavier, A. \& Almeida, A. S. A. (2017). Políticas locais e impactos na conceção da experiência turística em espaços urbanos - os casos do Bairro Alto e da Mouraria, Lisboa. Revista Brasileira de Gestão e Desenvolvimento Regional G\&DR, 13(2), 322-350.

\section{NotA BIOGRÁFICA}

António Sérgio Araújo de Almeida é Professor Adjunto na Escola Superior de Turismo e Tecnologia do Mar (ESTM) do Politécnico de Leiria. Doutor em Ciências do Turismo pela Universidade de Perpignan, França. É licenciado em Relações Internacionais e é membro integrado no CiTUR - Centro de Investigação, Desenvolvimento e Inovação em Turismo. É Coordenador do Mestrado em Turismo e Ambiente da ESTM e Subdiretor da ESTM. 
ORCID: https://orcid.org/0000-0002-3758-7656

Email: antonio.s.almeida@ipleiria.pt

Morada: Escola Superior de Turismo e Tecnologia do Mar - Campus 4 Santuário Nossa Senhora dos Remédios, 2520-641 Peniche - Portugal

* Submetido: $28-02-2018$

* Aceite: 01-07-2018 